\title{
DIAGNÓSTICO DA ARBORIZAÇÃO NAS CALÇADAS DE GURUPI, TO
}

\author{
DIAGNOSIS OF THE URBAN AFFORESTATION IN THE SIDEWALKS OF GURUPI, TO
}

\author{
Lucicléia Mendes de Oliveira ${ }^{1}$, André Ferreira dos Santos², Patrícia Aparecida de Souza ${ }^{3}$, Kaio Cesar \\ Cardoso de Lima Fonseca Alves ${ }^{4}$, Marcos Giongo ${ }^{5}$
}

\section{RESUMO}

Para usufruir dos benefícios da arborização urbana é necessário planejá-la adequadamente para proporcionar uma convivência harmônica entre as plantas, os elementos construídos e o homem. A pesquisa objetivou avaliar a situação da arborização quanto ao espaço disponível para o desenvolvimento das árvores e a distribuição destas nas calçadas de Gurupi, Tocantins. Foram coletados os seguintes dados: nome das vias públicas, espécies, altura e diâmetro da copa, danos nas calçadas, posição de plantio, tipos de conflitos, bem como as dimensões de calçadas e vias públicas. Foram inventariados 1942 exemplares vegetais e verificou-se alta concentração de Licania tomentosa (Benth.) $(70,88 \%)$, sendo esta uma árvore de grande porte, favorece o conflito por espaço físico e gera problemas quando próxima de calçadas, fiação elétrica e construções. Constatou-se ainda, área livre insuficiente, o que limita o desenvolvimento das plantas e indica a possibilidade de problemas de afloramento de raízes e danos nas calçadas. Conclui-se que a arborização precisa ser melhorada com a adoção de medidas como a compatibilização do espaço para o desenvolvimento das árvores, adequar o porte arbóreo à dimensão da calçada e via pública, restaurar calçadas e arborizar algumas ruas.

Palavras-chave: Espaçamento; Conflitos; Planejamento urbano.

\section{ABSTRACT}

In order to enjoy the benefits of urban trees, it is necessary to plan for harmonious coexistence among plants, buildings and man. The objective of this research was to evaluate the situation of the urban trees regarding the available space for the development of the trees and the distribution of these on the sidewalks of Gurupi, Tocantins. The data collected were: name of public roads, species, height and crown diameter, damage to the sidewalks, planting position, types of conflicts and the dimensions of sidewalks and public roads. A total of 1942 plants were inventoried and it was verified high concentration of Licania tomentosa (Benth.) $(70.88 \%)$, being this a large sized tree, it favors the conflict by physical space and generates problems when is close to sidewalks, electrical wiring and constructions. It has been found yet, an insufficient free area, which limits the plants development and indicates the possibility of root outcrops problems and damages in the sidewalks. It is concluded that the urban trees need to be improved with the adoption of measures like the compatibilization of the space for the trees development, to adapt the tree size to the size of the sidewalk and public road, to restore sidewalks and to afforest some streets.

Keywords: Spacing; Conflicts; Urban planning.

Recebido em 02.12.2016 e aceito em 24.03.2017

1 Bióloga, Pós-Doutoranda em Ciências Florestais e Ambientais, Universidade Federal do Tocantins - lucicleiabiologa@gmail.com 2 Eng. Florestal, Dr. Prof. do Programa de Pós-Graduação em Ciências Florestais e Ambientais, UFT - andrefs@uft.edu.br

3.Eng. Florestal, Dra. Profa. do Programa de Pós-Graduação em Ciências Florestais e Ambientais, UFT patriciaapsouza@uft.edu.com.br

4 Eng. Florestal, Mestrando do Programa de Pós-Graduação em Ciências Florestais e Ambientais, UFT - kcclfa@hotmail.com

5 Eng. Florestal, Dr. Prof. do Programa de Pós-Graduação em Ciências Florestais e Ambientais, UFT - giongo@uft.edu.br 


\section{INTRODUÇÃO}

A arborização presente no ambiente urbano pode proporcionar diferentes funções ecológicas, tais como: redução da poluição do ar, elevação da umidade relativa, amenizar ruídos, servir como referencial urbano, valorização estética e, ainda, satisfazer os requisitos sociais e econômicos. Portanto, se faz necessário administrar a vegetação urbana de acordo com os princípios técnicos e científicos, evitando-se o empirismo e amadorismo, deste modo, é indispensável conhecer o patrimônio arbóreo da cidade através de um inventário para identificar os possíveis problemas e consequentemente lançar as estratégias de manejo e replanejamento (SILVA; PAIVA; GONÇALVES, 2007).

Algumas diretrizes básicas para a implantação de projetos de arborização consistem em: verificar previamente as infraestrutura física da cidade; quais equipamentos estão presentes; localização das instalações aéreas e subterrâneas; quais as dimensões de ruas, calçadas e se existe recuo em relação às construções; qual o tipo de vegetação existente; devem ser respeitadas as legislações bem como o patrimônio municipal; plantar espécies de porte compatível com as instalações da área urbana e; também envolver a população como agente participativo na conservação e preservação da flora urbana; utilizar preferencialmente espécies nativas e diversificar as espécies utilizadas, entre outros aspectos (SMAS, 2013).

O planejamento da arborização é indispensável já que a ausência do mesmo ou o planejamento inadequado pode resultar em diversos problemas. Raber e Rebelato (2010) observaram na cidade do Colorado, RS, as seguintes irregularidades: exemplares danificando calçadas, pouca área livre disponível para o desenvolvimento do vegetal, porte arbóreo inadequado para o espaço disponível, árvores tocando a fiação elétrica, espécies exóticas em excesso e abundância de uma espécie em relação as demais, o que caracteriza um aspecto paisagístico monótono.

Tal situação é comum em diversas cidades brasileiras onde foram verificadas a distribuição irregular das espécies arbóreas, pois enquanto algumas espécies arbóreas apresentam valores superiores a $30 \%$ ou mais da população, outras são representadas por apenas um exemplar (PIRES et al., 2010; BARRETO et al., 2014; MEIRA et al., 2015). Além disso, a incompatibilidade do porte das árvores em relação a estrutura urbana pode resultar em danos nas calçadas, destruição das construções e danificação da fiação aérea, os quais demandam a necessidade de realizar medidas corretivas como podas ou substituição de árvores (BENATTI et al., 2012).

Portanto, para desfrutar dos benefícios da arborização, segundo Batista et al. (2013), é essencial um planejamento adequado, assim como a criação de programas que contemplem sobre o planejamento das dimensões de plantio da espécie, época, data e local, assim como o 
local de instalação de serviços urbanos como redes de esgoto. Além disso, é essencial a manutenção das espécies, recuperação da arborização existente e diversificação florística com ênfase nas espécies nativas.

Silva, Fidelis e Castro (2011) acrescentam ainda que para obter apenas benefícios da arborização é necessário planejar e ter conhecimento sobre diversas leis, tais como: o código florestal brasileiro; lei orgânica municipal, plano diretor do município e leis complementares; lei de parcelamento e uso do solo urbano e o plano viário municipal; e ainda as que dispõem sobre o mobiliário urbano e de saneamento.

O planejamento da arborização é essencial de forma que as árvores sejam escolhidas de forma adequada para cumprir o seu papel a curto, médio e logo prazo, entretanto, se esta função não for atendida o diagnóstico surge como alternativa para avaliar a situação da arborização e identificar os possíveis problemas que precisam ser solucionados. Portanto, se faz necessário o estudo para identificar os prováveis entraves da arborização como forma de replanejar determinadas áreas e também subsidiar o planejamento de outras.

Diante do exposto, a pesquisa objetivou avaliar a situação da arborização quanto ao espaço disponível para o desenvolvimento das árvores e a distribuição das mesmas nas calçadas de Gurupi, Tocantins, como requisito para diagnosticar os possíveis problemas a fim de auxiliar a gestão da arborização da área avaliada.

\section{MATERIAL E MÉTODOS}

\section{Área de estudo}

A área estudada se encontra em Gurupi, no sul do Tocantins, cujas coordenadas geográficas são: latitude 1143'45" sul, longitude 4904'07" oeste e altitude de $287 \mathrm{~m}$; limita-se com seis cidades e está distante $245 \mathrm{~km}$ de Palmas (SEPLAN, 2012). O clima da região é do tipo C2wA'a" úmido subúmido com moderada deficiência hídrica, conforme a classificação de Thornthwaite (SEPLAN, 2013). A estimativa da população em 2015 foi 83.7072 habitantes, densidade demográfica de 41,80 hab/km² e área territorial 1.836,081 km² (IBGE, 2010).

Para a localização das avenidas e ruas da área de estudo foi utilizado o mapa viário do município no qual constam os respectivos nomes de identificação. A área amostrada (Figura 1) foi composta por 13 avenidas e 10 ruas, das quais foi tomada como unidade amostral a quadra. Sendo assim, foram inventariadas 108 quadras (cerca de 145 ha, representando aproximadamente $9 \%$ da área urbana total do município), com exceção das áreas verdes e propriedades particulares. 

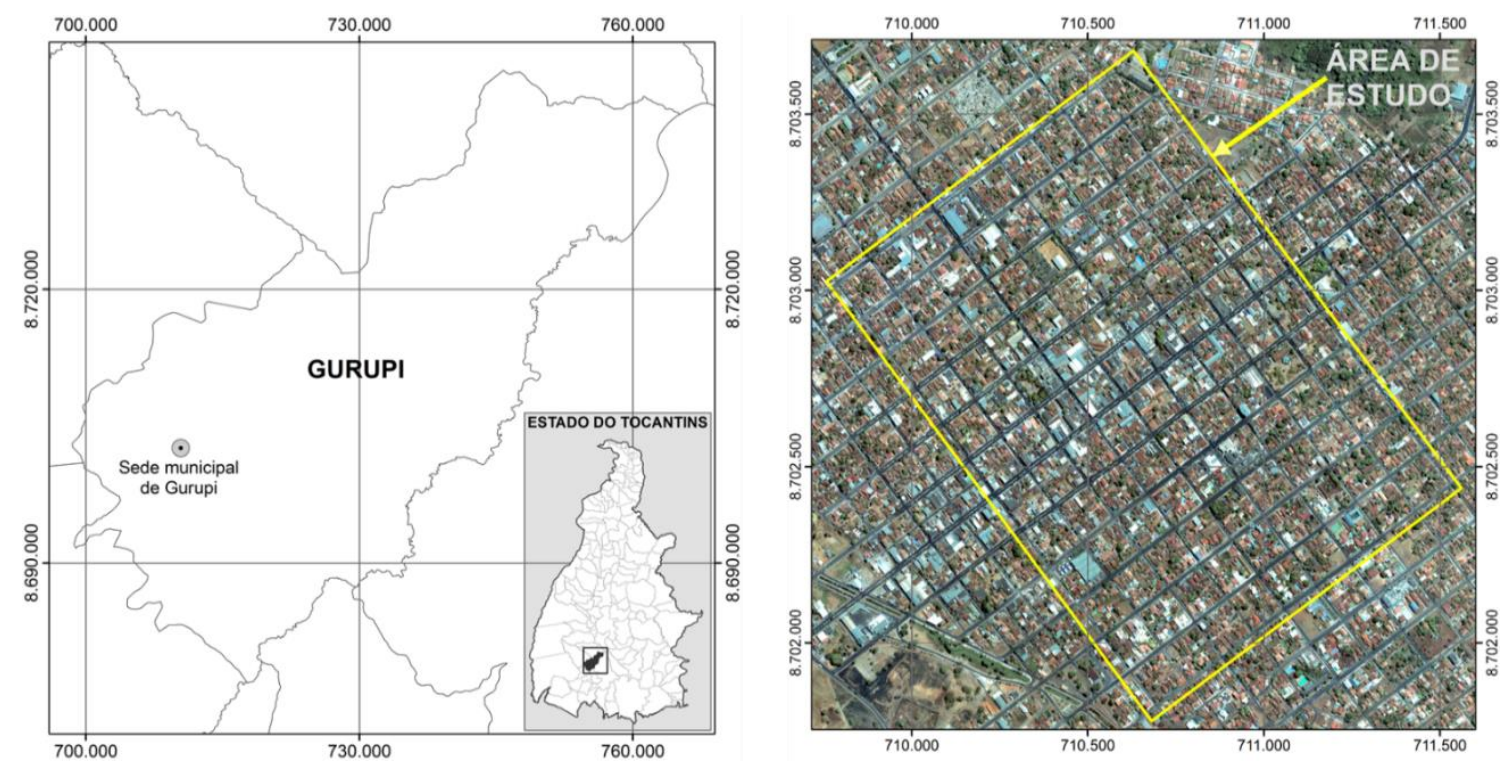

Figura 1. Localização da área de estudo

Figura 1. Location of study area

\section{Coleta e avaliação dos dados}

A coleta dos dados foi realizada nas ruas e avenidas de Gurupi durante os meses de fevereiro a maio de 2014. As informações obtidas foram: nome das vias públicas, número da quadra, espécies, altura total, diâmetro da copa, danos nas calçadas, posição de plantio, dimensões de calçadas e vias públicas, conflitos entre os elementos da malha urbana e as plantas, conforme descrito a seguir.

Os exemplares arbóreos e arbustivos foram identificados inicialmente por nomes populares e, ainda em campo, também foi realizado registro fotográfico e coleta de amostras botânicas para serem identificadas por meio de comparação com bibliografias e auxílio de especialistas do Herbário de Porto Nacional, localizado no município de Porto Nacional-TO. Para a classificação das famílias botânicas foi adotado o sistema Angiosperm Phylogeny Group III (APG III, 2009). As espécies também foram classificadas quanto à origem em nativas e exóticas.

A altura total foi estimada com o auxílio do equipamento clinômetro haglöf. Posteriormente, os indivíduos foram agrupados quanto à fase de desenvolvimento sendo consideradas mudas aqueles com altura inferior a $1,50 \mathrm{~m}$ e os demais exemplares foram separados em três categorias: pequeno (menor que $6 \mathrm{~m}$ ), médio (entre 6 e $12 \mathrm{~m}$ ) e grande porte (acima de $12 \mathrm{~m}$ ) baseando-se em SMAS (2013).

Para a determinação do diâmetro da copa foi realizada a média de duas medidas, sendo uma no sentido norte-sul e a segunda no sentido leste oeste. Posteriormente os valores 
foram agrupados em classes: I- 0,00 - 3,00 m; II- 3,00 - 6,00 m; III- 6,00 - 9,00 m e IV para os valores superiores a 9,00 m, segundo Araújo et al. (2009).

Os danos nas calçadas provocados pelas raízes foram agrupados em três categorias: 1 (ausente) - raiz não causa nenhum dano na calçada; 2 (aponta/trinca) - raiz causa trinca nas calçadas; 3 (quebra) - a raiz fica exposta e destrói a calçada (MELO; LIRA FILHO; RODOLFO JúNIOR, 2007).

Para a posição de plantio, tomou-se como base em manuais de arborização (SMAS, 2013; PORTO; BRASIL, 2013), sendo assim foram aferidas as distâncias e classificadas em duas categorias cada uma: a) distância da árvore ao meio fio, considerada menor que 0,6m e a outra maior ou igual a 0,6 m; b) distância da árvore às construções e/ou muros, considerado menor que $2 \mathrm{~m}$ e a outra maior ou igual a $2 \mathrm{~m}$; c) espaçamento entre árvores, sendo a primeira categoria até $8 \mathrm{~m}$ e a outra maior ou igual a $8 \mathrm{~m} \mathrm{e}$; d) a área livre de crescimento onde foi avaliada a disponibilidade de espaço disponível para o desenvolvimento da planta, baseada nas dimensões do referido formato, cujos resultados foram expressos em metros quadrados.

O espaço em torno das árvores foi agrupado em três seguintes categorias, tomando como referência Emer et al. (2013): boa - quando a área livre de pavimento era igual ou superior a um metro quadrado; pouca - quando inferior a um metro quadrado; e ausente locais completamente impermeabilizados. Também foi verificada a presença e a ausência de cinta, ou seja, estrutura física em torno da área livre.

As dimensões de calçadas coletadas foram largura e comprimento e das vias públicas (rua/avenida) foi a largura, todas medidas com o auxílio de fita métrica de $50 \mathrm{~m}$. Para calcular o potencial de ocupação das árvores por quilômetro de calçada foi adotado como critério o espaçamento de $8 \mathrm{~m}$ entre árvores (SILVA et al., 2007).

Para os conflitos entre os mobiliários da área urbana e as plantas foram identificados os tipos (poste, casa/muro e sinalização) e medida a distância entres os elementos (poste, sinalização, garagem, esquina e fossa) e as árvores, os quais foram separados posteriormente em duas categorias, como descrito a seguir: poste - menor e maior que $4 \mathrm{~m}$; sinalização menor e maior que $5 \mathrm{~m}$; garagem - menor e maior que $1 \mathrm{~m}$; esquina - menor e maior que $5 \mathrm{~m}$ e; fossa - menor e maior que $1 \mathrm{~m}$, segundo SMAS (2013). Em seguida os dados foram digitados em planilha eletrônica, e posteriormente foram confeccionadas tabelas e figuras.

Para a análise das variáveis diâmetro de copa, área livre para o desenvolvimento, danos causados por raízes, distância em relação ao meio fio, cinta de proteção e os referentes aos conflitos entre os imobiliários urbanos - poste, sinalização, garagem, esquina e fossa foram considerados apenas os exemplares adultos. Na sequência foi determinada a frequência das plantas por espécie em função do total de indivíduos encontrados, bem como a frequência 
de espécies nativas e exóticas. Em seguida, as demais determinações foram avaliadas através da elaboração de gráficos.

\section{RESULTADOS E DISCUSSÃO}

Neste inventário foi observada a presença de 1942 indivíduos, dos quais 1769 eram adultos e 173 jovens ou mudas, sendo distribuídos em 17 famílias e 52 espécies, compostas por 27 exóticas e 25 nativas da flora brasileira (Tabela 1). Contatou-se que Licania tomentosa (Benth.) Fritsch foi a espécie dominante, a qual representa $70,88 \%$ da população avaliada, porcentagem que está fora da faixa de 10 a $15 \%$ recomendada por diversos autores.

Tabela 1. Relação de espécies encontradas na arborização da área de estudo em Gurupi/TO, Brasil segundo a família, espécie, nome popular, número total de indivíduos (NTI), frequência (F\%), origem $(\mathrm{O})$ em nativas $(\mathrm{N})$ e exóticas $(\mathrm{E})$ e porte $(\mathrm{P})$

Table 1. Relation of species found in the afforestation of the study area in Gurupi / TO, Brazil, according to the family, species, popular name, total number of individuals (NTI), frequency $(\mathrm{F} \%)$, origin $(\mathrm{O})$ in native $(\mathrm{N})$ and exotic $(\mathrm{E})$ and size $(\mathrm{P})$

\begin{tabular}{|c|c|c|c|c|c|c|}
\hline FAMILIA & Nome científico & Nome popular & NTI & $F(\%)$ & $\mathbf{O}$ & $\mathbf{P}$ \\
\hline \multirow[t]{4}{*}{ Anacardiaceae } & Anacardium occidentale L. & Caju & 6 & 0,31 & $\mathrm{~N}$ & $\mathrm{M}$ \\
\hline & Mangifera indica L. & Mangueira & 41 & 2,11 & $\mathrm{E}$ & G \\
\hline & Schinus molle L. & Aroeira-salsa & 12 & 0,62 & $\mathrm{~N}$ & M \\
\hline & Spondias mombin L. & Cajá & 4 & 0,21 & $\mathrm{~N}$ & G \\
\hline Annonaceae & Annona squamosa L. & Fruta-do-conde & 6 & 0,31 & $\mathrm{~N}$ & $\mathrm{G}$ \\
\hline \multirow[t]{2}{*}{ Apocynaceae } & Aspidosperma tomentosum Mart. & Piquiá & 1 & 0,05 & $\mathrm{~N}$ & M \\
\hline & Thevetia peruviana (Pers.) Schum. & $\begin{array}{l}\text { Chapéu-de- } \\
\text { napoleão }\end{array}$ & 5 & 0,26 & $\mathrm{~N}$ & $\mathrm{P}$ \\
\hline \multirow[t]{6}{*}{ Bignoniaceae } & Crescentia cujete L. & Coité & 4 & 0,31 & $\mathrm{~N}$ & $P$ \\
\hline & Jacaranda brasiliana (Lam.) & Caroba & 3 & 0,15 & $\mathrm{~N}$ & M \\
\hline & Handroanthus albus (Cham.) Mattos & Ipê-amarelo & 22 & 1,13 & $\mathrm{~N}$ & $\mathrm{G}$ \\
\hline & $\begin{array}{l}\text { Tabebuia aurea (Manso) Benth. \& Hook } \\
\text { Handroanthus impetiginosus (Mart. ex DC.) }\end{array}$ & Craíba & 1 & 0,05 & $\mathrm{~N}$ & $\mathrm{G}$ \\
\hline & Mattos & Ipê-roxo & 5 & 0,26 & $\mathrm{~N}$ & M \\
\hline & Tecoma stans (L.) Juss. ex Kunth & Ipê-mirim & 3 & 0,15 & $E$ & $P$ \\
\hline \multirow{16}{*}{$\begin{array}{l}\text { Caricaceae } \\
\text { Chrysobalanacea } \\
\text { e } \\
\text { Combretaceae } \\
\text { Ebenaceae } \\
\text { Fabaceae }\end{array}$} & Carica papaya L. & Mamão & 2 & $\begin{array}{l}0,10 \\
70,8\end{array}$ & $E$ & M \\
\hline & Licania tomentosa (Benth.) Fritsch & Oiti & 1378 & 8 & $\mathrm{~N}$ & $\mathrm{G}$ \\
\hline & Terminalia catappa L. & Castanhola & 18 & 0,93 & $E$ & $\mathrm{G}$ \\
\hline & Diospyros kaki L.f. & Caqui & 1 & 0,05 & $E$ & $\mathrm{G}$ \\
\hline & Adenanthera pavonina Linnaeus & Tento-carolina & 1 & 0,05 & $E$ & G \\
\hline & Andira vermifuga Mart. ex Benth. & Angelim & 4 & 0,21 & $\bar{N}$ & M \\
\hline & Bauhinia variegata (L.) Benth & Pata-de-vaca & 9 & 0,46 & $E$ & M \\
\hline & Caesalpinia pluviosa Sin & Sibipiruna & 95 & 4,89 & $\mathrm{~N}$ & G \\
\hline & Caesalpinia pulcherrima (L.) Sw. & Flamboyant-mirim & 8 & 0,41 & $E$ & $P$ \\
\hline & Cassia fistula L. & Cássia-imperial & 23 & 1,18 & $E$ & G \\
\hline & Delonix regia (Boj. ex Hook.) Raf. & Flamboyant & 2 & 0,1 & $E$ & G \\
\hline & Erythrina indica Lam. & Brasileirinho & 2 & 0,1 & $E$ & M \\
\hline & Inga vera Willd. & Ingá & 2 & 0,1 & $\mathrm{~N}$ & G \\
\hline & Leucaena latissiliqua (L.) Gillis & Leucena & 1 & 0,05 & $E$ & G \\
\hline & Mimosa caesalpiniaefolia Benth. & Sansão-do-campo & 1 & 0,05 & $\mathrm{~N}$ & M \\
\hline & Shysolobium paraiba (Vell.) S.F. Blake & Paricá & 1 & 0,05 & $\mathrm{~N}$ & G \\
\hline \multirow{5}{*}{$\begin{array}{l}\text { Lamiaceae } \\
\text { Malpighiaceae } \\
\text { Malvaceae }\end{array}$} & Tectona grandis L.F. & Teca & 2 & 0,1 & $E$ & G \\
\hline & Malpighia glabra L. & Acerola & 3 & 0,15 & $E$ & $P$ \\
\hline & Apeiba tibourbou Aubl. & Pente-de-macaco & 1 & 0,05 & $\mathrm{~N}$ & G \\
\hline & Pachira aquatica Aubl. & Munguba & 87 & 4,48 & $\mathrm{~N}$ & G \\
\hline & Sterculia chica A. St. Hil. & Chichá & 1 & 0,05 & $\mathrm{~N}$ & G \\
\hline
\end{tabular}




\begin{tabular}{|c|c|c|c|c|c|c|}
\hline \multirow[t]{2}{*}{ Meliaceae } & Azadirachta indica A. Juss. & $\mathrm{Nim}$ & 9 & 0,46 & $E$ & $\mathrm{G}$ \\
\hline & Cedrela fissilis Vell. & Cedro-rosa & 1 & 0,05 & $\mathrm{~N}$ & G \\
\hline \multirow[t]{4}{*}{ Moraceae } & Artocarpus heterophyllus Lam. & Jaqueira & 1 & 0,05 & $\mathrm{E}$ & G \\
\hline & Ficus benjamina L. & Fícus & 25 & 1,29 & $E$ & $\mathrm{G}$ \\
\hline & Ficus mexiae Standl. & Figueira-preta & 3 & 0,15 & $\mathrm{~N}$ & M \\
\hline & Morus nigra L. & Amora & 3 & 0,15 & $E$ & $M$ \\
\hline \multirow[t]{5}{*}{ Myrtaceae } & Eucalyptus sp. & Eucalipto & 1 & 0,05 & $E$ & $\mathrm{G}$ \\
\hline & Psidium guajava L. & Goiabeira & 7 & 0,36 & $\mathrm{~N}$ & $M$ \\
\hline & Syzygium cumini (L) Skeels & Jambolão & 3 & 0,15 & $E$ & M \\
\hline & Syzygium jambos L.(Alston) & Jambo-do-campo & 1 & 0,05 & $E$ & M \\
\hline & Syzygium malaccense (L.) Merr. \& LMPerry & Jambo-roxo & 39 & 2,01 & $E$ & $\mathrm{G}$ \\
\hline \multirow[t]{4}{*}{ Rutaceae } & Carolus linnaeus (L.) - Burm.f & Limão & 1 & 0,05 & $E$ & $P$ \\
\hline & Citrus reticulata Blanco & Lima & 1 & 0,05 & $E$ & $P$ \\
\hline & Citrus sinensis (L) Osbeck & Laranja & 1 & 0,05 & $E$ & $P$ \\
\hline & Murraya paniculata (L.) Jack & Jasmim-laranjeira & 83 & 4,27 & $\mathrm{E}$ & $P$ \\
\hline \multirow[t]{4}{*}{ Sapindaceae } & Litchi chinensis Sonn. & Lixia & 6 & 0,31 & $E$ & $\mathrm{G}$ \\
\hline & Magonia pubescens A.St.-Hil & Tingui & 1 & 0,05 & $\mathrm{~N}$ & M \\
\hline & Talisia esculenta (A. St.-Hil.) Radlk & Pitomba & 1 & 0,05 & $\mathrm{~N}$ & M \\
\hline & & & * & 100 & & \\
\hline
\end{tabular}

*Total de indivíduos adultos e jovens (mudas), respectivamente, 1769 e 173 e frequência de indivíduos por porte: Pequeno $(P)=5,61 \%$; Médio $(M)=3,29 \%$ e Grande $(G)=91,09 \%$.

A dominância de poucas espécies é frequente em diversas cidades brasileiras, sendo que em Goiandira (GO) e Matupá e Colíder (MT) apresentaram em comum Licania tomentosa (PIRES et al., 2010; ALMEIDA; RONDON NETO, 2010), provavelmente devido os estados serem próximos o que pode ter influenciado na aceitabilidade dessa espécie. Tal situação, além de reduzir a diversidade de espécies, coloca em risco a vida das plantas, pois aumenta a probabilidade de serem atacadas por pragas e doenças (MILANO; DALCIN, 2000).

Outro fator não desejável na arborização é a presença de árvores de grande porte implantadas em calçadas geralmente estreitas e associada a maior representatividade das mesmas, conforme foi constatado por Barreto et al. (2014) no bairro de Valente, Bahia, para as espécies Pachira aquatica Aubl. (31,04\%) e Ficus benjamina L. (20,23\%), as quais também fazem parte da arborização de Gurupi.

Esses resultados despertam a atenção para o gerenciamento da arborização de Gurupi, desta forma se faz necessário diversas medidas como: diversificar a distribuição de indivíduos por espécie para evitar o risco de pragas e doenças; evitar o plantio da espécie dominante; ampliar a diversidade florística com ênfase naquelas consideradas nativas da região; verificar a compatibilidade do porte arbóreo para o local onde a árvore será transplantada; e também escolher árvores cujo sistema radicular não comprometa a estrutura física das calçadas.

Neste estudo foi verificado que a maioria das árvores (Tabela 1) possui grande porte, no entanto nota-se que $62,8 \%$ dos indivíduos têm altura inferior a $6 \mathrm{~m}$ (Figura 2A). Esses valores sugerem que as plantas foram submetidas a podas para se enquadrar às estruturas físicas da cidade devido à convivência desarmônica delas em relação ao local onde estão situadas ou devido à arborização ser recente. A explicação para os baixos valores de altura, 
baseando-se em Araújo et al. (2009), é devido a espécie mais abundante ter sido implantada na cidade a pouco tempo e, ainda, por causa das frequentes podas de correção e àquelas destinadas a fins estéticos.
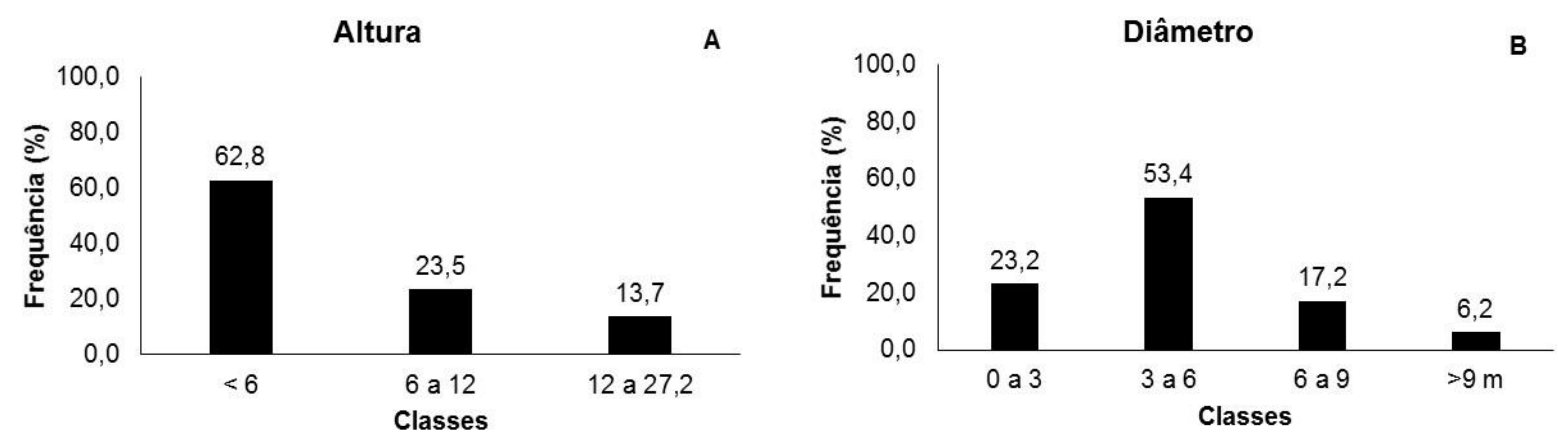

Figura 2. Classes de frequência de altura (A) e diâmetro de copa (B) da arborização de calçadas de Gurupi, Tocantins

Figure 2. Frequency classes of height $(A)$ and crown diameter $(B)$ of the afforestation of sidewalks of Gurupi, Tocantins

O uso excessivo de espécies arbóreas de grande porte pode gerar problemas para os órgãos administrativos, população e as empresas responsáveis pelos serviços de energia elétrica o que demanda um custo elevado para a manutenção constante da vegetação urbana, principalmente relativo às podas das copas (BATISTEL et al., 2009), por isso é importante realizar inventários para subsidiar o planejamento e o manejo da arborização de forma compatível com a estrutura física da cidade.

Nas cidades de Matupá e Colíder no Mato Grosso, por exemplo, a altura máxima dos indivíduos foi na faixa de $8,0 \mathrm{~m}$ os quais são compatíveis com a altura da fiação de média tensão (9,0 m), entretanto alguns indivíduos podem entrar em conflito se colocados sob a baixa tensão que é de 7,0 a 7,5 m (ALMEIDA; RONDON NETO, 2010). Comparando as alturas das árvores das cidades de Mato Grosso com algumas de Gurupi, cujo porte é superior a $12 \mathrm{~m}$, é notório que vários exemplares entram em conflito com a fiação elétrica e isso resulta em podas frequentes para se adequarem ao espaço físico e manter distâncias mínimas de segurança. Isso mostra mais uma vez que medidas corretivas devem ser realizadas para as espécies serem enquadradas na estrutura urbana e, por isso, é preferível a introdução de espécies de porte pequeno e médio sob as redes de distribuição de energia.

Além da altura da árvore o tamanho da copa formada também é um fator importante a ser considerado na arborização, desta forma ao avaliar o diâmetro (Figura 2B) constatou-se que $76,6 \%$ dos exemplares possui valores compreendidos entre 0 e $6 \mathrm{~m}$ e somente $6,2 \%$ eram maiores que $9 \mathrm{~m}$. Esses resultados sugerem que diversos exemplares foram podados para evitar conflitos com as construções e a fiação elétrica. Semelhantemente a este estudo, Araújo 
et al. (2009) explicam o reduzido tamanho das copas das árvores devido a necessidade de podas corretivas para adequá-las ao espaço urbano.

E ao avaliar os possíveis danos provocados pelas raízes (Figura 3A), constatou-se que a maioria dos exemplares $(52,5 \%)$ não gerou nenhum problema visível nas construções e calçadas, enquanto os demais foram responsáveis por trincas $(34,3 \%)$ e destruição (13\%) como resultado do afloramento das raízes para a superfície. Esses problemas são consequência da falta de espaço disponível para o pleno desenvolvimento das árvores, os quais podem ser confirmados pelo reduzido tamanho da área livre, ou seja, inferior a $1 \mathrm{~m}^{2}$, da maioria das árvores inventariadas (76,3\%); além disso, os casos mais preocupantes se justificam devido a impermeabilidade da área livre (13,2\%) que funciona como barreira física impedindo a infiltração da água no solo e, consequentemente, limitando o crescimento das plantas (Figura 3B).
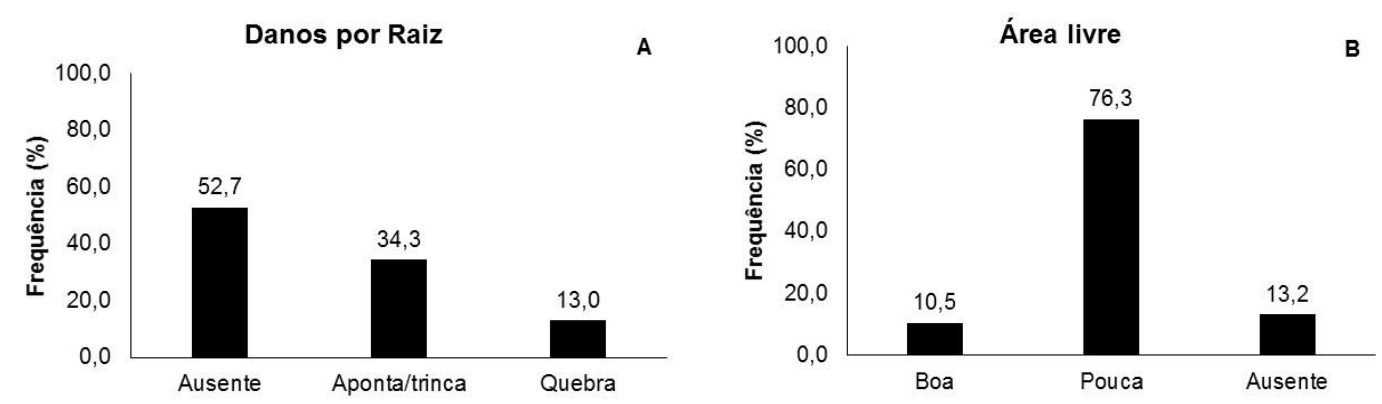

Figura 3. Classes de frequência de variação de danos por raiz (A) e área livre de crescimento (B) da arborização urbana de Gurupi, Tocantins

Figure 3. Frequency classes of damage variation by root $(A)$ and free growth area $(B)$ of the urban afforestation of Gurupi, Tocantins

A restrita disponibilidade de espaço na área livre de crescimento associado ao grande porte das árvores dificulta o aproveitamento de água e nutrientes pela planta, e por conseguinte as raízes exercem pressão sob as calçadas (RABER; REBELATO, 2010).

As árvores proporcionam benefícios ambientais, econômicos e sociais para os estabelecimentos residenciais e comerciais, mas 0 uso crescente de superfícies impermeabilizadas limita o desenvolvimento delas e colocam em riscos as suas vidas. Diante disso, o uso de pavimentação permeável constitui um método promissor para melhorar o crescimento e o desenvolvimento das plantas na área urbana (MULLANEY; LUCKE; TRUEMAN, 2015).

O porte das árvores deve ser criteriosamente escolhido para evitar possíveis conflitos com a estrutura urbana, além disso, deve-se dá preferência as espécies que apresentam raízes profundas. Partindo dessa premissa, segundo Santos et al. (2015), as espécies Ficus benjamina e Terminalia catappa (Sw) DC não são indicadas para a arborização de ruas porque 
possuem sistema radicular superficial que provoca a destruição de canteiros e calçadas. Do mesmo modo, Meira et al. (2015) constataram que Schinus molle L. também apresenta potencial de entrar em conflito com a estrutura urbana. Portanto, é necessária atenção quanto a escolha das espécies para o local onde serão destinadas, compatibilidade com o espaço físico e, ainda, manutenção.

Considerando o posicionamento de plantio das árvores, nota-se que $19,8 \%$ dessas estavam numa distância inferior a $0,6 \mathrm{~m}$ em relação ao meio fio (Figura 4A) e 32,4\% encontravam-se a menos de $2 \mathrm{~m}$ das construções (Figura 4B), e com relação ao espaçamento entre plantas (Figura 4C) verificou-se que apenas 28,9\% estavam a uma distância superior a 8 $\mathrm{m}$, lembrando que a maioria das árvores são de grande porte, e com relação à cinta de proteção (Figura 4D) apenas 10,8\% dos indivíduos possuíam. A cinta é considerada vantajosa devido evitar que a água junto com produtos de limpeza escorra para a área livre, portanto a existência desta proteção impede a intoxicação das plantas. Esses dados confirmam a necessidade de replanejamento da arborização desta cidade para haver uma convivência harmônica entre as árvores e os elementos da malha urbana.
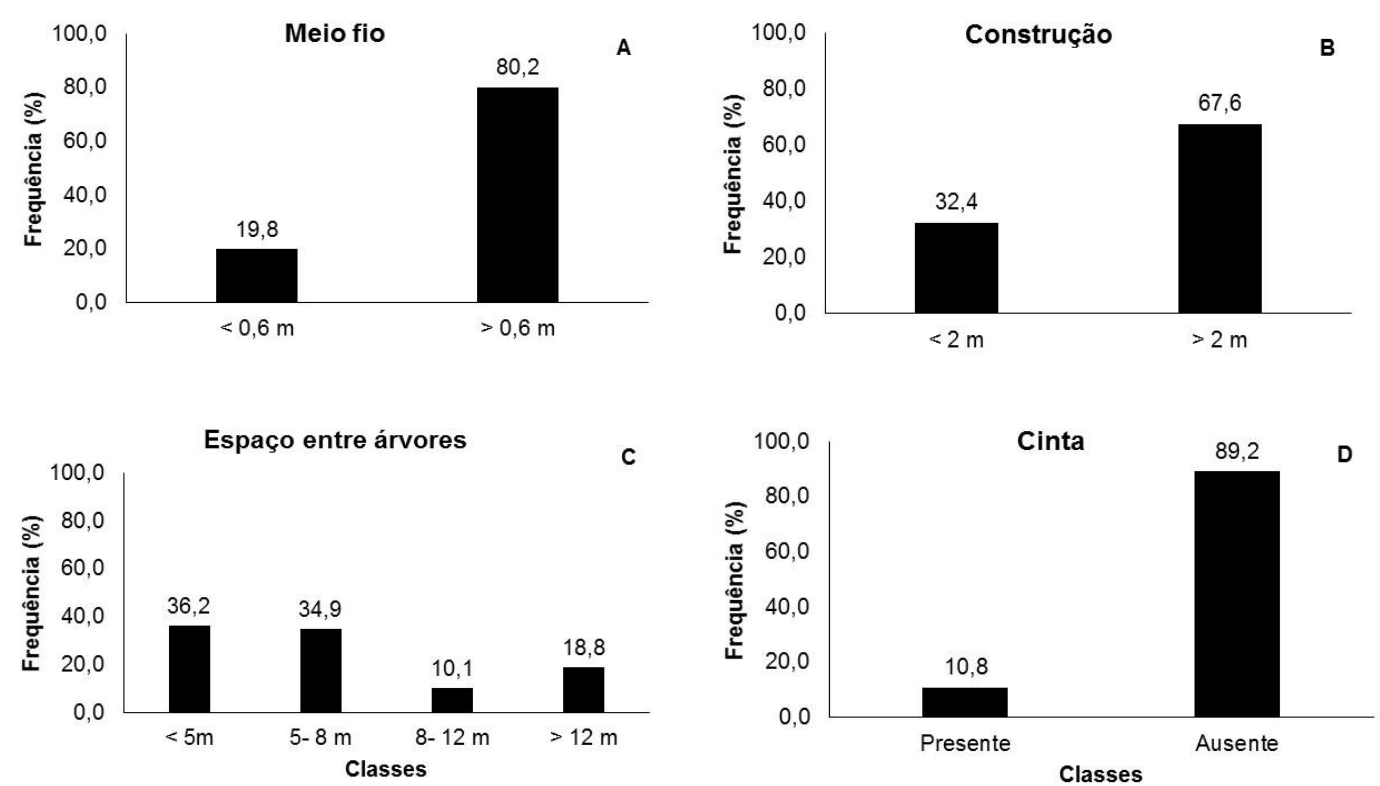

Figura 4. Posições de plantio das árvores em relação ao meio fio (A), construção (B), espaço entre árvores (C) e cinta de proteção (D)

Figure 4. Planting positions of trees in relation to the curb (A), construction (B), space between trees $(C)$ and protective strap (D)

Utilizando como referência informações dos manuais de arborização de Recife, PE e Belém, PA quanto ao posicionamento das plantas nota-se que é necessário replanejar a arborização de Gurupi, considerar o distanciamento das árvores em relação às estruturas da área urbana e igualmente o porte da espécie escolhida. Conforme o manual do Recife (SMAS, 
2013), árvore de qualquer porte deve ser plantada a $2 \mathrm{~m}$ em relação às construções, enquanto para a distância entre as árvores deve-se respeitar um critério, sendo de 5, 8 e 12 metros segundo o porte, respectivamente, pequeno, médio e grande. Em relação ao meio fio recomenda-se a distância de 0,3 m para espécies de pequeno porte e 0,6 m para as demais, no entanto, nenhum dos manuais faz referência à cinta de proteção (PORTO; BRASIL, 2013).

Comparando os resultados do presente estudo com as recomendações do manual do Recife (SMAS, 2013) nota-se que o posicionamento de $32,4 \%$ das árvores em relação as construções apresenta-se inadequado, pois estão localizadas a menos de $2 \mathrm{~m}$. Ademais, o distanciamento entre as árvores também necessita de intervenções, pois $71,1 \%$ dos exemplares estão espaçadas a menos de $8 \mathrm{~m}$. Esse resultado chama atenção para um replanejamento, especialmente, para as árvores de grande porte que representou 91,09\% da arborização de calçadas (Tabela 1) as quais poderão gerar custos adicionais com as operações de podas para evitar e corrigir os conflitos com as construções e a fiação aérea.

Situação semelhante a arborização de Gurupi foi observada por Barreto et al. (2014) no município de Valente, Bahia, onde se constatou a necessidade de podas corretivas para atenuar os conflitos entre as árvores e o mobiliário urbano. Esse quadro sugere a necessidade de intervenções para melhorar a qualidade da arborização urbana em prol da convivência harmônica entre plantas e seres humanos para que ambos possam usufruir dos benefícios.

Para complementar as informações de plantio foi averiguado também a largura de ruas $(6,14-14,97 \mathrm{~m})$, avenidas $(12,20-19,90 \mathrm{~m})$, calçadas $(1,00 \mathrm{a} 15,75 \mathrm{~m})$ e canteiro central (1,83 a 3,00 m), sendo que o espaçamento das árvores no último variou 0,0 a 76,84 m. Com relação as calçadas, $31,1 \%$ dos indivíduos estavam situados em locais com menos de $2 \mathrm{~m}$ de largura, $13,9 \%$ entre 2,0 e 2,5 m e 55,1\% das plantas em passeios com largura superior a 2,5 m. Comparando-se a largura das calçadas com o porte das plantas é possível inferir que há incompatibilidade de espaço já que $91,09 \%$ dos indivíduos são de grande porte (ver tabela 1).

Portanto, segundo Silva, Fidelis e Castro (2011), para se obter o sucesso na arborização urbana é essencial seguir e ter um planejamento, conhecer a área, escolher a espécie adequada para as condições locais, bem como quantidade, qualidade e distribuição das plantas de forma adequada - onde as pessoas tenham acesso seguro - e ainda, adotar medidas que contribuam para a convivência harmônica entre os pedestres e as árvores do entorno.

Para Miranda e Carvalho (2009), o conhecimento da largura de calçadas também é um fator relevante para a escolha de espécies arbóreas destinadas a arborização. Partindo dessa premissa, diversos manuais indicam as recomendações de acordo com o porte arbóreo. Devido a carência de manual de arborização do estado do Tocantins, o presente estudo utilizou como base as recomendações do manual do Recife (SMAS, 2013), o qual indica árvores de 
pequeno porte para passeios entre 1,50 - 2,00 m, árvores de médio e pequeno porte para aqueles entre 2,00 - 2,50 m e árvores de grande e médio porte para os passeios com larguras maiores que $2,50 \mathrm{~m}$.

Quanto ao número de árvores presentes nas vias públicas observa-se que há uma variação de 39 a 171 (Tabela 2) e ao adotarmos como referência um espaçamento entre elas de 8 metros, seguindo a recomendação da SMAS (2013), para haver a completa ocupação de $1 \mathrm{~km}$ de calçada foi possível constatar que caberia 125 indivíduos. Seguindo esse raciocínio podemos notar que apenas as avenidas Goiás, Pará, Maranhão e Mato Grosso apresentam árvores a mais, pois estão bem adensadas nestas vias. Lembrando que esse espaçamento adotado no estudo é para árvores de médio porte, contudo se considerasse o espaçamento de $12 \mathrm{~m}$ entre árvores caberia apenas 83 exemplares em $1 \mathrm{~km}$ de calçada e mesmo assim, as demais vias públicas continuariam com déficit de indivíduos.

Tabela 2. Vias públicas, número de árvores nas calçadas por via pública, quilômetros de calçada, número de árvores atuais/Km, número ideal e déficit de árvores, porcentagem de árvores presentes e déficit de árvores em Gurupi, Tocantins, Brasil

Table 2. Public roads, number of trees on sidewalks per public roads, kilometers of sidewalk, number of current trees $/ \mathrm{km}$, ideal number and tree deficit, percentage of present trees and deficit tree in Gurupi, Tocantins, Brazil

\begin{tabular}{cccccccc}
\hline $\begin{array}{c}\text { Vias } \\
\text { Públicas }\end{array}$ & $\begin{array}{c}\text { No de } \\
\text { árvores }\end{array}$ & $\begin{array}{c}\text { Km de } \\
\text { calçada }\end{array}$ & $\begin{array}{c}\text { No de árvores } \\
\text { atuais/km }\end{array}$ & $\begin{array}{c}\text { No ideal de } \\
\text { árvores } / \mathbf{K m}\end{array}$ & $\begin{array}{c}\text { Déficit de } \\
\text { árvores/km }\end{array}$ & $\begin{array}{c}\text { Árvores } \\
\text { presentes } \\
(\%)\end{array}$ & $\begin{array}{c}\text { Déficit de } \\
\text { árvores } \\
(\%)\end{array}$ \\
\hline 1 & 77 & 2,64 & 29,12 & 125 & 95,88 & 23,30 & 76,70 \\
2 & 74 & 2,62 & 28,29 & 125 & 96,70 & 22,64 & 77,36 \\
3 & 55 & 2,61 & 21,03 & 125 & 103,97 & 16,83 & 83,17 \\
4 & 63 & 2,59 & 24,30 & 125 & 100,70 & 19,44 & 80,56 \\
5 & 57 & 2,53 & 22,54 & 125 & 102,46 & 18,04 & 81,96 \\
6 & 75 & 2,57 & 29,23 & 125 & 95,77 & 23,38 & 76,62 \\
7 & 59 & 2,61 & 22,64 & 125 & 102,36 & 18,11 & 81,89 \\
8 & 51 & 2,59 & 19,71 & 125 & 105,29 & 15,77 & 84,23 \\
9 & 39 & 2,61 & 14,97 & 125 & 110,03 & 11,97 & 88,03 \\
10 & 44 & 2,58 & 17,06 & 125 & 107,94 & 13,65 & 86,35 \\
Alagoas & 99 & 1,96 & 50,58 & 125 & 74,42 & 40,46 & 59,54 \\
Amazonas & 155 & 1,93 & 80,24 & 125 & 44,76 & 64,19 & 35,81 \\
Ceará & 71 & 1,94 & 36,54 & 125 & 88,46 & 29,23 & 70,77 \\
Goiás & 133 & 0,96 & 138,69 & 125 & $-13,69$ & 110,96 & $-10,96$ \\
Maranhão & 171 & 0,95 & 180,19 & 125 & $-55,19$ & 144,15 & $-44,15$ \\
Mato Grosso & 128 & 0,95 & 134,74 & 125 & $-9,74$ & 107,79 & $-7,79$ \\
Pará & 140 & 0,95 & 146,72 & 125 & $-21,72$ & 117,38 & $-17,38$ \\
Paraíba & 76 & 1,94 & 39,22 & 125 & 85,78 & 31,37 & 68,63 \\
Paraná & 63 & 1.89 & 33,35 & 125 & 91,65 & 26,68 & 73,32 \\
Pernambuco & 80 & 1,94 & 41,25 & 125 & 83,75 & 32,00 & 67,00 \\
Piauín & 58 & 1,93 & 30,07 & 125 & 94,93 & 24,06 & 75,94 \\
Santa Catarina & 67 & 1,80 & 37,25 & 125 & 87,75 & 29,80 & 70,20 \\
São Paulo & 107 & 1,89 & 56,69 & 125 & 68,31 & 45,35 & 54,65 \\
\hline Total & $\mathbf{1 9 4 2}$ & $\mathbf{4 6 , 9 6}$ & $\mathbf{4 1 , 3 5}$ & $\mathbf{1 2 5}$ & $\mathbf{8 3 , 6 5}$ & $\mathbf{3 3 , 0 8}$ & $\mathbf{6 6 , 9 2}$ \\
\hline & & & & & & &
\end{tabular}

No presente estudo foram encontradas cerca de 41 árvores por quilômetro de calçadas (Tabela 2), valor (43 árvores) próximo do verificado por Raber e Rebelato (2010), no Colorado, Rio Grande do Sul. Enquanto Almeida e Rondon Neto (2010) verificaram valores de 
densidade de árvores $/ \mathrm{km}$ de calçada de 66,2 em Matupá e 71,3 em Colíder. Apesar dos valores encontrados em Gurupi ser considerado mediano quando comparado com os autores citados é necessário realizar o planejamento da arborização e tomar os devidos cuidados com relação às espécies, os critérios e as técnicas para o plantio.

Com relação aos conflitos entre as árvores e os elementos da malha urbana (Figura $5 \mathrm{~A}$ ) foi observado que apenas $13,1 \%$ tocavam nas casas, $2,3 \%$ nos postes, $0,1 \%$ na sinalização e 0,6\% atingiam mais de uma estrutura física. Os dados revelam que há necessidade de podas de manutenção nessas árvores para evitar possível transtornos como: a proliferação de mofo nas paredes; localização abaixo dos postes acarretando o escurecimento de ruas durante a noite; e o contato das árvores com as placas de sinalização que atrapalham a visão dos motoristas e ainda podem facilitar a ocorrência de acidentes de trânsito.
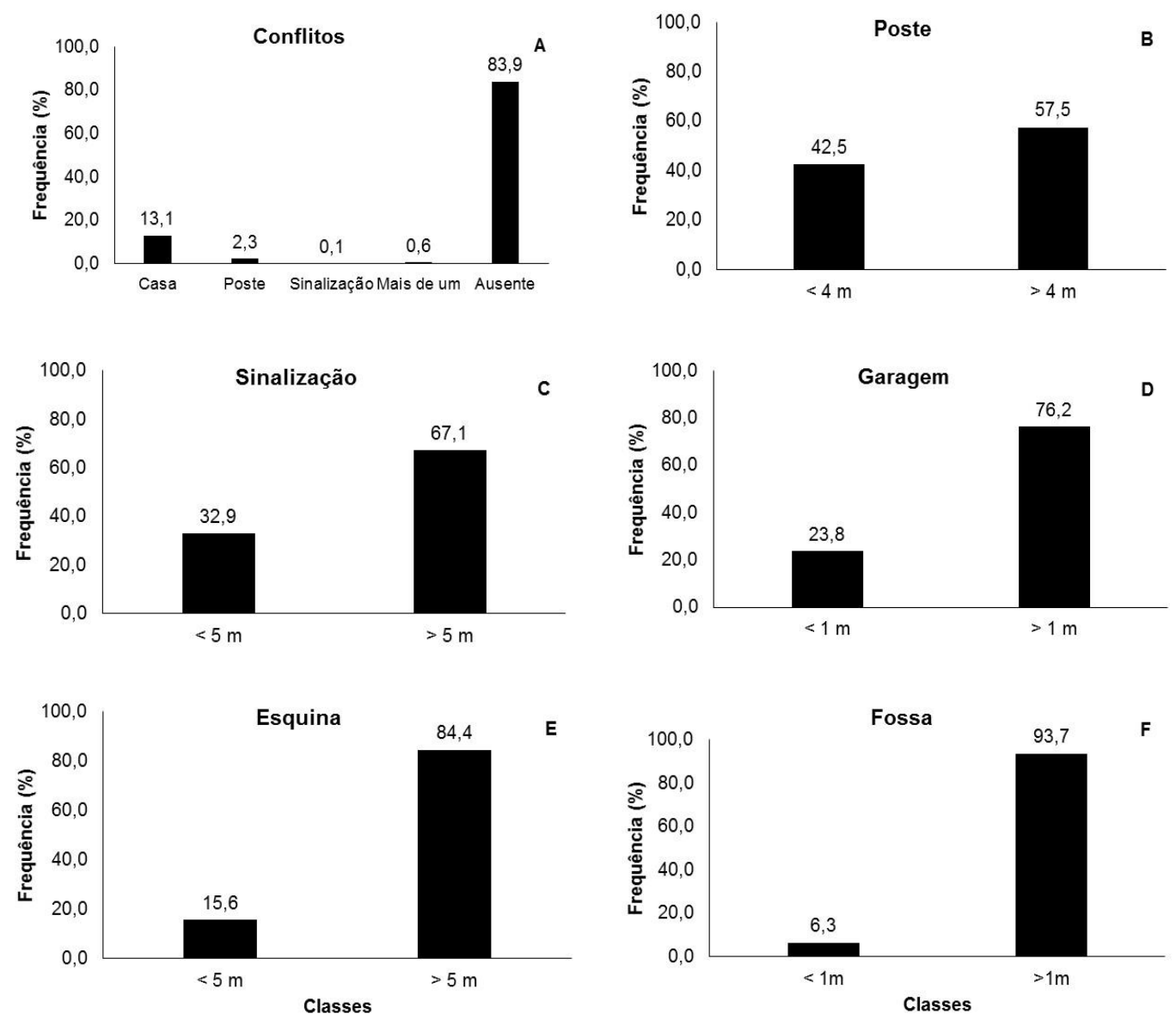

Figura 5. Conflitos entre as estruturas físicas (A), distância das árvores em relação ao poste (B), sinalização $(C)$, garagem $(D)$, esquina $(E)$ e fossa $(F)$ na arborização de calçadas de Gurupi (TO)

Figure 5. Conflicts between physical structures $(A)$, distance of trees in relation to the post $(B)$, signaling $(C)$, garage (D), corner (E) and septic tanks (F) in the afforestation of Gurupi (TO) sidewalks

Resultados semelhantes foram encontrados por Pires et al. (2010) em Goiandira (GO) quanto aos conflitos das árvores com as estruturas da cidade onde registraram-se poucos 
casos atuais e potenciais de conflitos entre a arborização urbana e a iluminação pública, muros e outras construções, ou seja, as árvores estavam bem alocadas espacialmente nas calçadas. Por outro lado, em Gurupi é necessário maiores intervenções como a remoção e a substituição de indivíduos por outros para adequar ao espaço disponível ou adequar o mobiliário urbano às árvores.

A posição de plantio das árvores em relação a alguns componentes físicos da cidade foi realizada de maneira equivocada, uma vez que muitos exemplares foram plantados em distâncias não seguras para o pleno desenvolvimento das árvores sem gerar conflitos com as construções, especialmente, por não considerar o porte. A consequência dessa decisão imatura é ocorrência de vários transtornos como dificuldade de acesso das pessoas para entrarem na garagem de suas casas, pouca iluminação de parte da cidade, atrapalha a visibilidade dos motoristas quando as árvores ficam em frente das placas de sinalização e esquinas, as raízes podem quebrar as calçadas e destruir as construções subterrâneas como as fossas.

Características semelhantes quanto à arborização da cidade Gurupi também foram observadas na cidade de Remígio, Paraíba, onde os autores explicam que os problemas da arborização se devem ao uso de árvores de porte inadequado para o espaço disponível. Frequentemente são encontradas árvores altas em calçadas estreitas que acarretam desestruturação do piso e trincamento das estruturas dos muros devido à pressão exercida pelas raízes (BATISTA et al., 2013).

De modo geral, pode-se constatar que em Gurupi foram encontrados diversos problemas relacionados a arborização como consequência da ausência de planejamento e, ou, planejamento inadequado. Assim, sugere-se a adoção das seguintes medidas corretivas: diversificação da quantidade de espécie e a distribuição de indivíduos; implantar árvores de pequeno e médio porte, para calçadas estreitas, e as de grande porte, para as calçadas largas e com espaço físico tridimensional; expandir as áreas livres e colocar faixas verde nas calçadas; adequar as distâncias das plantas em relação aos mobiliários; arborizar vias públicas com arborização escassa e implantar árvores com sistema radicular profundo.

\section{CONCLUSÃO}

$\mathrm{Na}$ arborização de ruas de Gurupi (TO), em alguns trechos de calçada foi constatada a necessidade de restauração e insuficiência de área livre para o desenvolvimento das árvores, bem como largura de calçadas insuficientes para o adequado desenvolvimento das árvores. 
A falta de planejamento e, ou, o planejamento inadequado desta cidade, no trecho estudado, é responsável por diversos conflitos como a destruição de calçadas, ausência de árvores em diversos segmentos de calçadas, porte arbóreo incompatível com a largura da calçada e também aspecto monótono devido a dominância de poucas espécies, neste caso representada por Licania tomentosa.

\section{AGRADECIMENTOS}

Os autores agradecem à ajuda dos alunos do curso de Engenharia Florestal nas etapas de coleta de dados e aos professores que contribuíram com a identificação das espécies.

\section{REFERÊNCIAS}

ALMEIDA, D. N.; RONDON NETO, R. M. Análise da arborização urbana de duas cidades da região norte do estado de Mato Grosso. Revista Árvore, Viçosa, v. 34, n. 5, p. 899-906, 2010.

ANGIOSPERM PHYLOGENY GROUP (APG). An update of the Angiosperm Phylogeny Group classification for the orders and families of flowering plants: APG III. Botanical Journal of the Linnean Society, [S.I], v. 161, n. 2, p. 105-121, 2009.

ARAÚJO, A. C; RIBEIRO, I. A. M.; MORAIS, MS.; ARAÚJO, J. L. O. Análise quali-quantitativa da arborização no bairro presidente Médici, Campina Grande-PB. Revista da Sociedade Brasileira de Arborização Urbana, Piracicaba, v. 4, n. 1, p. 133-144, 2009.

BARRetO, A. M. R.; PAULA, A.; BARReTO, P. A. B.; BARRETO, M. G. M. R. Diagnóstico da arborização urbana do bairro Dionísio Mota, município de Valente, Estado da Bahia. Enciclopédia Biosfera, Goiânia, v. 10, n. 19, p. 2108-2119, 2014.

BATISTA, F. A.; CHAVES, T. P.; FELISMINO, D. C.; DANTAS, I. C. Inventário quali-quantitativo da arborização urbana na cidade de Remígio, Paraíba. Revista de Biologia e Farmácia, Campina grande, v. 9, n. 1, p. 70-83. 2013.

BATISTEL, L. M.; DIAS, M. A. B.; MARTINS, A. S.; RESENDE, I. L. M. Diagnóstico qualitativo e quantitativo da arborização urbana nos bairros Promissão e Pedro Cardoso, Quirinópolis, Goiás. Revista da Sociedade Brasileira de Arborização Urbana, Piracicaba, v. 4, n. 3, p. 110-129, 2009.

BENATTI, D. P.; TONELLO, K. C.; ADRIANO JÚNIOR, F. C.; SILVA, J. M. S.; OLIVEIRA, I. R.; ROLIM, E. N.; FERRAZ, D. L. Inventário arbóreo-urbano do município de Salto de Pirapora, SP. Revista Árvore, Viçosa, v. 36, n. 5, p. 887-894, 2012. 
EMER, A. A.; SILVA, L.; CADORIN, D. A.; MELLO, N. A. Avaliação quantitativa e qualitativa da arborização do bairro Santa Terezinha na cidade de Pato Branco (PR). Ambiência, Guarapuava, v. 9, n. 1, p. 129-143. 2013.

INSTITUTO BRASILEIRO DE GEOGRAFIA E ESTATÍSTICA (IBGE) 2010. Informações estatísticas. Disponível em: <http://cidades.ibge.gov.br/xtras/perfil.php?lang=\&codmun $=170950 \&$ search=||infogr\%E1ficos:-informa\%E7\%F5es-completas > Acesso em: 12 jul. 2016 .

MULLANEY, J.; LUCKE, T.; TRUEMAN, S. J. A review of benefits and challenges in growing street trees in paved urban environments. Landscape and Urban Planning, [S.I], v.134, p.157166, 2015.

MEIRA, G. R. N; TEXEIRA, G. G. M.; VENTURIN, P. R. F.; GOTTSTEIN, P.; CAXAMBU, M.G. Avaliação quali-quantitativa de espécies arbóreas no perímetro urbano da cidade de Corumbataí do Sul - PR. Revista da Sociedade Brasileira de Arborização Urbana, Piracicaba, v. 10, n. 4, p. 36-49, 2015.

MELO, R. R.; LIRA FILHO, J. A.; RODOLFO JÚNIOR, F. Diagnóstico qualitativo e quantitativo da arborização urbana no bairro Bivar Olinto, Patos, Paraíba. Revista da Sociedade Brasileira de Arborização Urbana, Piracicaba, v. 2, n. 1, p. 64-80, 2007.

MILANO, M. S.; DALCIN, E. C. Arborização de vias públicas. Rio de Janeiro: Light, 2000. 226p.

MIRANDA, T. O.; CARAVALHO, S. M. Levantamento quantitativo e qualitativo de indivíduos arbóreos presentes nas vias do bairro da Ronda em Ponta Grossa-PR. Revista da Sociedade Brasileira de Arborização Urbana, Piracicaba, v 4, n. 3, p. 143-157, 2009.

PIRES, N. A. M.; MELO, M. S.; OLIVEIRA, D. E.; XAVIER-SANTOS, S. A arborização urbana do município de Goiandira/GO - caracterização quali-quantitativa e propostas de manejo. Revista da Sociedade Brasileira de Arborização Urbana, Piracicaba, v. 5, n. 3, p. 185-205, 2010.

PORTO, L. P. M; BRASIL, H. M. S. Manual de Orientação Técnica da Arborização Urbana de Belém: guia para planejamento, implantação e manutenção da arborização em logradouros públicos. Belém: Universidade Federal Rural da Amazônia, 2013. 108p.

RABER, A. P.; REBELATO, G. S. Arborização viária do município de Colorado, RS - Brasil: análise quali-quantitativa. Revista da Sociedade Brasileira de Arborização Urbana, Piracicaba, v. 5, n. 1, p. 183-199, 2010.

SANTOS, C. Z. A.; FERREIRA, R. A.; SANTOS, L. R.; SANTOS, L. I.; GOMES, S. H.; GRAÇA, D. A. S. Análise qualitativa da arborização urbana de 25 vias públicas da cidade de Aracaju SE. Ciência Florestal, Santa Maria, v. 25, n. 3, p. 751-763, 2015.

SECRETARIA DE MEIO AMBIENTE E SUSTENTABILIDADE (SMAS) - Prefeitura da Cidade do Recife. Manual de arborização: orientações e procedimentos técnicos básicos para a implantação e manutenção da arborização da cidade do Recife. 1. Ed, Recife: [s.n.], 2013. 71 p.

SECRETARIA DO PLANEJAMENTO E DA MODERNIZAÇÃO DA GESTÃO PÚBLICA (SEPLAN) 2012. Atlas do Tocantins: subsídios ao planejamento da gestão territorial. Disponível em: <http://www.seplan.to.gov.br/Portal/acontece/atlas2012>. Acesso em: 03 jul. 2014. 
SECRETARIA DO PLANEJAMENTO E DA MODERNIZAÇÃO DA GESTÃO PÚBLICA (SEPLAN) 2013. GURUPI - SEPLAN - Governo do Estado do Tocantins. Disponível em: <http://www.seplan.to.gov.br/Arquivos/download/Municipios_Perfil_2013/Gurupi.pdf> Acesso: 03 jul. 2014.

SILVA, A. G.; PAIVA, H. N.; GONÇALVES, W. Avaliando a arborização urbana. Viçosa, MG: Aprenda Fácil, 2007. 346p.

SILVA, M. L.; MOCCELLIN, R.; WEISSHEIMER, D. I.; ZBORALSKI, A. R.; FONSECA, L.; RODIGHIERO, D. A. Inventário e sugestões para arborização em via pública de Pato Branco/PR. Revista da Sociedade Brasileira de Arborização Urbana, Piracicaba, v. 2, n. 1, p. 100-108, 2007.

SILVA, F. F.; FIDELIS, M. E. A.; CASTRO, P. F. Arborização e acessibilidade em calçada: comentários sobre o deslocamento entre Campi da Universidade Federal Fluminense. Revista da Sociedade Brasileira de Arborização Urbana, Piracicaba, v. 6, n. 3, p. 43-63, 2011. 